\title{
“Desentoca o arsenal!": a estrutura de sentimento na guerra de facções, analisada a partir do proibidão
}

\author{
"Flush out the arsenal!": the structure of feeling in the war of \\ factions analyzed from funk proibidão
}

https://doi.org/10.34112/2317-0972a2019v37n77p93-110

\section{Luiz Eduardo Lopes Silva ${ }^{1}$}

RESUMO: O presente artigo analisa a estrutura de sentimento da guerra de facções, representada no gênero musical denominado funk proibidão, objeto deste estudo. O funk proibidão produzido na periferia de São Luís, no estado do Maranhão, segue a linha dos funks que abordam as experiências das primeiras instituições de autorregulação e autodeterminação do crime surgidas nos estados do Rio de Janeiro (em fins dos anos 1970) e de São Paulo (no início da década de 1990). Respectivamente, CV e PCC. Diante da análise das letras dos proibidões catalogados na pesquisa, concluiu-se que a materialidade do funk de facção é a base constituinte de uma forma concreta de socialização de experiências de uma fração da juventude periférica (sujeita a políticas estatais de encarceramento e extermínio), que vê no crime sua única possibilidade de ascensão social, agora organizada a partir de uma articulação inédita cadeia-favela.

PALAVRAS-CHAVE: Williams; proibidão; facção; guerra.

AвSTRACT: The present article analyzes the structure of feeling from the war of factions represented in the musical gender called funk proibidão, that's our subject of study. The Brazilian funk proibidão produced on São Luís' outskirts, in the state of Maranhão, follows the line of funks which talks about experiences of the first institutions of self-regulation and self-determination of crime that have arisen in the states of Rio de Janeiro (in the late

1. Universidade Federal do Maranhão, Pinheiro, MA, Brasil. 
"Desentoca o arsenal!": a estrutura de sentimento na guerra de fações, analisada...

1970's) and of São Paulo (in the early 199o's). CV (Red Command) and PCC (First Capital Command), respectively. Given the analysis of proibidões lyrics catalogued in the research, we concluded that funk of faction materiality is the constituent basis of a concrete form of socialization of experiences from a part of the young people who live on the outskirts (subject to government policy of incarceration and extermination), whom had seen in crime their unique chance of upward mobility, nowadays organized from a unprecedented articulation between jail and slum.

KEYWORDS: Williams; funk proibidão; war of factions.

\section{INTRODUÇÃO: NOÇÕES PRELIMINARES E PROCEDIMENTOS METODOLÓGICOS}

O tema do presente trabalho é entender a estrutura de sentimento ${ }^{2}$ no interior da guerra de facções representada no gênero musical denominado funk proibidão, nosso objeto de estudo. O funk proibidão produzido na periferia de São Luís, no Estado do Maranhão, segue a linha dos funks que abordam as experiências das organizações pioneiras surgidas nos estados do Rio de Janeiro (em fins dos anos 1970) e de São Paulo (início da década de 1990), quando, a partir de uma luta de classes renhida no cárcere, surgem as primeiras instituições de autorregulação e autodeterminação no mundo do crime, respectivamente, Comando Vermelho (CV) e Primeiro Comando da Capital (PCC).

Definimos facçães como instituições de autorregulação e autodeterminação no mundo do crime, a partir de uma leitura de conjunto da ampla literatura acumulada sobre esse universo (BIONDI, 2018; FELTRAN, 2018; LESSING, 2008; MANSO; DIAS, 2018; MARQUES, 2010; MATTOS, 2016, dentre outros). A nosso ver, processos metodológicos diversos demonstram que as facções são agentes estabilizadores no complexo unitário cadeia-favela, pois funcionam como mediadoras de conflitos nessa rede de sociabilidade, especialmente entre os indivíduos diretamente vinculados ao mundo do crime, mas não somente. Compostas em suas bases, majoritariamente, por jovens pobres periféricos, as façẽees, como instituição dessa fração de classe, encarnam um programa político de luta contra o Estado, articulado a partir da prisão, e enxergam como legítima e desejável a ascensão social pelo crime. Dentre diversas funções desse tipo de instituição, a autorregulação se dá mediante a

2. “'Estrutura de sentimento' é, como se sabe, o termo que Williams cunhou para descrever como nossas práticas sociais e hábitos mentais se coordenam com as formas de produção e de organização socioeconômica que as estruturam em termos do sentido que consignamos à experiência do vivido" (CEVASCO, 2001, p. 97). 
vigilância para que os contratos firmados entre parceiros numa empreitada criminal sejam cumpridos, o que inaugura novas formas de sociabilidade e compõe um novo padrão ético-político, baseado na autodeterminação que reivindica um modelo de "proceder" na vida do crime. Facções rivais, estupradores, delatores, dentre outros execráveis, são considerados inimigos, por representarem, de alguma forma, a negação radical a esses parâmetros autoestabelecidos por essas instituições ${ }^{3}$.

As facções exercem para dentro de suas redes o papel de autorregulação e autodeterminação, ao mesmo tempo que para fora, isto é, para aqueles que se opõem aos seus parâmetros autoestabelecidos (inimigos, policiais, delatores, etc.), elas impõem a guerra. Essa instituição está fundada na urgência da guerra desde o seu nascimento, e por isso essa é uma face decisiva da constituição do seu ser e do seu modus operandi. Assim, nesse universo, as representações em torno da paz e da guerra estão intimamente articuladas. Na estrutura de sentimento das facções, plasmada no proibidão, a paz é alcançada como resultado da guerra contínua que as facções travam contra aqueles considerados execráveis.

Considerando a nossa posição teórica a seguir, temos em conta a hipótese de que, representando em suas letras o cotidiano desses sujeitos, a materialidade do funk de facção é a base constituinte de uma forma concreta de socialização de experiências dessa juventude periférica (sujeita a políticas estatais de encarceramento e extermínio), que luta por ascensão social, instrumentalizando-se e conectando-se, através de processos violentos, à gestão de mercados ilegais. Nesse passo, o proibidão captura numa forma estética a estrutura de sentimento (WILLIAMS, 1979, 2013) da luta desses sujeitos sociais que se organizam a partir de uma conexão inédita entre a cadeia e a favela. Essa juventude periférica impulsionada pelo encarceramento massivo presente desde o início dos anos 1990, pôde, ao vivenciar situações de opressão extrema nas cadeias, perceber a si mesma como classe e, desde então, passou a se objetivar sob a forma organizativa daquilo que ficou popularmente conhecido como facção. Essa instituição forjada em anos de massacres carcerários toma para si a ascensão social pelo crime, parte indispensável de seu programa político. O proibidão deu "forma semântica" à experiência vivida nesse decurso; afinal,

3. Isso não significa dizer que os chamados "Comandos Cariocas": CV, Amigos dos Amigos (A.D.A) e Terceiro Comando Puro (TCP) se organizem de maneira idêntica ao PCC. No Rio de Janeiro a estrutura organizativa da facção funciona colada na estrutura do tráfico; o mesmo não acontece em São Paulo com o PCC. Para uma reflexão entre aproximações e diferenças do comércio varejista de drogas do Rio de Janeiro e São Paulo, ver Hirata e Grillo (2017). 
"Desentoca o arsenal!": a estrutura de sentimento na guerra de fações, analisada...

a "emergência de uma nova estrutura de sentimento pode ser mais bem relacionada ao surgimento de uma classe" (WILLIAMS, 2013, p. 155). O proibidão, dessa maneira, se constitui como veículo de socialização de experiências dessas organizações coletivas, que no mundo do crime (FELTRAN, 2011) representam a encarnação de "tradições, sistemas de valores, ideias e formas institucionais" (THOMPSON, 1987, p. 10) dessa fração de classe.

À luz desse quadro teórico, nos debruçaremos sobre o corpus do objeto - a análise dos proibidões, especialmente das letras - a partir dos fundamentos teórico-metodológicos indicados. No curso desta pesquisa, que vem se desenvolvendo há mais de 2 anos $^{4}$, elegemos 120 funks que estão catalogados em fichas. Suas letras foram transcritas, e foram catalogadas também diversas informações, como: data de publicação, número de visualizações, informações relevantes sobre o $\mathrm{MC}^{5}$, facções tematizadas, temas abordados, etc. Todos esses dados ainda estão sendo tabulados e analisados, e deles aqui apresentaremos um entendimento provisório, mas já resultado de uma caminhada substancial.

Os proibidões catalogados são, em sua maioria esmagadora, produzidos pelas facções que atuam no Maranhão, principalmente o Bonde dos 40 e o Primeiro Comando do Maranhão (PCM), foco central da pesquisa. Há também muitos proibidões do Rio de Janeiro, por percebermos que as organizações cariocas, especialmente CV e A.D.A. (Amigos dos Amigos), bem como seus respectivos proibidões, exercem influência direta sobre as facções maranhenses. Contudo, foram também catalogados funks de todas as 5 regiões do país (totalizando 13 estados), que serão analisados para entendermos o lugar do Maranhão nesse complexo cenário nacional.

Para elegermos os 120 proibidões catalogados, mais de mil foram escutados e analisados ao longo de quase 3 anos. Utilizamos um critério primeiramente qualitativo: foram escolhidos aqueles cujas letras nos pareceram mais ricas do ponto de vista estético e documental ${ }^{6}$; também foram levados em conta os MC de maior destaque e seus respectivos funks, a maioria de alcance apenas local, mas alguns

4. Pesquisa realizada no Programa de Pós-Graduação em Educação da UFF, em nível de Doutorado, sob orientação do Professor Dr. Ronaldo Rosas Reis.

5. A sigla MC (Mestre de Cerimônias) se refere àquele artista que canta funk ou rap.

6. Há uma face documental do proibidão muito cara aos historiadores. Esse caráter documental ocupa uma posição importante na pesquisa que está em curso, pois um dos objetivos dela é analisar a história das facções maranhenses utilizando o proibidão como fonte. A ausência de pesquisas de fôlego, historiográficas ou sociológicas, sobre as facções maranhenses torna essa tarefa bastante difícil, ao mesmo tempo em que eleva a importância do trato cuidadoso desse rico material. 
com forte repercussão nacional. Utilizamos especialmente a plataforma do YouTube como fonte de pesquisa e catalogação dos funks.

\section{O PROIBIDÃO COMO FORMA SEMÂNTICA DA JUVENTUDE PERIFÉRICA FACCIONADA}

O hip-hop, gênero musical que dá, em parte, origem ao funk, surge primeiramente em solo norte-americano, mas sua origem pode ser rastreada na Jamaica, "pelo processamento em estúdios de gravações de rhythm and blues afro norte-americano" (PALOMBINI, 2013b, p. 141). O funk no Brasil foi ressignificado de diferentes formas ao longo do tempo e se difundiu exponencialmente, sendo consumido principalmente (mas não exclusivamente) nos subúrbios e nas favelas pelo Brasil afora. Não tardou para ofunk atrair para si olhares criminalizantes de diversos setores da sociedade. A sugestão legislativa de número 17/2017, que tentou criminalizar o funk, é apenas mais uma das diversas investidas repressivas por parte do Estado e de setores hegemônicos contra a produção cultural ligada à diáspora negra e da periferia.

Renovadas política e sonoramente com as invenções do disco long-play e de toda uma complexidade tecnológica, as culturas negras transformam-se em hip-hop em solo estadunidense e se espalham criativamente pelo mundo, inclusive no Brasil. Por canais informais de comunicação, o hip-hop é desvinculado do seu local de origem histórica chegando a diferentes territórios do globo com realidades parecidas. Locais que possuem como pano de fundo experiências urbanas marcadas por formas similares, mas não idênticas, de racismo, pobreza e segregação espacial [...] Nos subúrbios e nas favelas da cidade do Rio de Janeiro, o hip-hop da Flórida recebe o nome de funk. (LOPES; FACINA, 2012, p. 194)

Há, entretanto, diversas subdivisões no funk, dentre as quais está o proibidão, que, por sua vez, se desdobra em duas categorias:

As categorias "proibido" e "proibidão" são frequentemente acionadas para fazer referência aos funks que abordam a temática da sexualidade de forma explícita - funk putaria - ou aos que produzem narrativas sobre o universo da criminalidade, tangenciando o cotidiano e as sociabilidades ligadas à noção de bandido. (NOVAES, 2016, p. 11) 
"Desentoca o arsenal!": a estrutura de sentimento na guerra de fações, analisada...

Assim, o termo proibidão carrega esse duplo significado, "de fato, na fala nativa a expressão pode significar tanto funks pornográficos quanto funks criminais" (VIEIRA, 2012, p. 18). Para não confundi-lo com sua vertente pornográfica, quando utilizarmos a designação proibidão, tomamos essa segunda acepção descrita acima, que se caracteriza por ser um gênero musical que aborda temas ligados ao mundo do crime. Podemos chamá-los também de funk de facção ou proibidão de facção, "que é como os funkeiros o definem quando querem enfatizar a diferença” (VIEIRA, 2012, p. 18). Em suma, "os chamados 'proibidões', [são] funks cantados pelos MCs, cujas letras supostamente fazem apologia ao crime, narrando histórias em que os traficantes justiceiros impuseram seu poder contra os oponentes e fizeram valer a sua lei" (CYMROT, 2013, p. 116).

No funk proibidão, o eu lírico do MC assume o ponto de vista do bandido e toda a sua visão de mundo. A crueza de suas letras pode impressionar os não iniciados. $\mathrm{O}$ batidão, quase sempre acelerado, é criativamente mixado com rajadas de fuzis e pistolas. Não é rara a presença de trechos de notícias jornalísticas colocadas de maneira irônica, normalmente no início dos funks, ora para debochar do discurso corporativo midiático em torno do crime, ora para "documentar" feitos dos quais se orgulham.

Assim, numa primeira leitura, o proibidão aparece imediatamente como uma representação apologética da violência e apenas isso! De fato, essa era a perspectiva inicial desta pesquisa. Foi pela violência de suas letras que inicialmente of funk proibidão nos chamou atenção. Contudo, ao nos aprofundarmos nesse universo, ouvindo mais de mil proibidões nos últimos três anos, produzidos em todas as regiões do País, e nos apropriarmos da produção bibliográfica sobre o tema, podemos perceber que esse é um universo muito mais rico do que supúnhamos e que aquela violência que aparece na superfície obnubila uma teia complexa de afetos e relações que ficam submersos e se articulam entre si contraditoriamente. O proibidão, ao passo que sintetiza símbolos de identidades coletivas, representando relações e papéis sociais, também engendra novas relações sociais, ajudando a transformar aquele universo. Afinal,

o funk pode ser compreendido como um meio de comunicação popular com grande influência sobre a juventude pobre. Expressando realidades múltiplas, servindo como diversão, transmitindo mensagens e, sobretudo, transformando em registro artístico a linguagem da favela, cheia de gírias e sentidos diversos da língua culta [...] Num contexto no qual cada vez mais as favelas são guetificadas por uma política de (in) segurança pública que é marcada pela criminalização da pobreza, o funk ganha uma 
importância comunicacional ainda maior, espécie de "jornal popular", no dizer de Mr. Catra. (LOPES; FACINA, 2012, p. 197)

Para além da violência presente na guerra de facções rivais representadas nas letras, também estão presentes no proibidão uma série de outras temáticas: solidariedade, sensualidade, amor, amizade, crítica social e outros tantos temas, como não poderia ser diferente, já que todos são sentimentos universais da vida humana. Da mesma forma como se revelam o sexismo, a homofobia e o bairrismo, o consumismo desenfreado e outros tantos infortúnios que assolam nossa época também são facilmente encontrados nas suas letras. Assim, quando tomamos para análise um objeto complexo como o funk proibidão, é preciso abarcá-lo em sua totalidade contraditória, sem pesar a mão para este ou aquele aspecto e sem escorregar nas armadilhas da aparência.

Dessa forma, ao examinar o funk proibidão a partir da ótica da guerra de facções, vemos essa violência representada não como faceta unitária desse complexo fenômeno, mas como locomotiva de uma narrativa daqueles cuja sobrevivência é uma luta diária de vida e de morte. Essa luta (essa guerra) pela sobrevivência (seja no cárcere, na favela ou na vida como um todo) parece ter na violência sua centralidade; entretanto, essa luta violenta só ganha sentido à medida que se articula com inúmeros outros sentimentos e aspirações. Não sendo a simples manifestação de uma irracionalidade bestial, como às vezes se supõe, essa violência, resultante de relações sociais marcadas pela desigualdade, é significada e ressignificada de diversas maneiras pelos próprios atores sociais desse universo, e o funk proibidão parece ser o veículo primordial de tal representação para esses setores, configurando-se assim como uma fonte privilegiada de análise. Afinal, a música popular ${ }^{7}$ pode ser tomada exemplarmente "como sintoma da eficácia de certas formas sociais gerais de auto-representação" (SOUZA, 2004, p. 41).

Mas, enfim, quem são os atores sociais do proibidão? Apesar de o eu lírico do MC assumir o papel do bandido, normalmente os MC não possuem nenhum envolvimento com o crime, segundo apontam Cymrot (2013), Facina (2013) Novaes (2016), Palombini (2013a), Vieira (2012) e outros. Os MC do proibidão normalmente são jovens moradores de periferia que simplesmente desejam retratar musicalmente sua realidade. Entretanto, há também os MC que estão vinculados

7. "A música popular, no Brasil, é uma produção discursiva muito forte e presente; talvez a mais forte em um país marcado pelo analfabetismo. A música popular aqui assumiu esta função de produzir sentido para a vida em sociedade, para as nossas diferenças, para as misérias e riquezas humanas desse país” (KEHL, 2004, p. 142). 
"Desentoca o arsenal!": a estrutura de sentimento na guerra de fações, analisada...

diretamente às facções e produzem músicas pelo País afora. No Maranhão podemos constatar alguns deles, que gravam suas músicas de maneira rudimentar nos presídios do Estado e depois lançam os vídeos (ou apenas os áudios) na internet, em sites de compartilhamento de mídia, como o YouTube. É o caso do primeiro grande sucesso do proibidão maranhense: "Ninguém nasceu bandido", gravado artesanalmente no Complexo Penitenciário de Pedrinhas, por MC Sadrak, do Bonde $\operatorname{dos} 40^{8}$, que viralizou pelas redes sociais no Maranhão no ano de 2014, não apenas pelo fato de citar a então governadora do estado, Roseana Sarney, como pelo vídeo, onde apareciam vários detentos, que chocaram a opinião pública mais por portarem celulares do que por estarem numa cela infecta e superlotada.

O funk de Sadrak vocaliza angústias presentes na vida do cárcere, visto como um lugar de opressão e sofrimento, que, entretanto, é o lugar por excelência onde se articulam as facções:

MC Sadrak: - Tá gravando? Divulga! Bonde dos 40! Papo reto! Diretamente da cadeia pra rua, moleque!

Ninguém nunca veio aqui pra saber da nossa vida

Qualquer coisa que acontece a imprensa sensacionaliza

Por isso é necessário a real divulgação

Do que acontece de verdade dentro e fora da prisão

Mesmo que não acredite nesse papo que eu te digo

Ninguém que tá aqui jamais nasceu bandido

Sem comida na panela, emprego, nem educação

Me diz aí por que a mídia não divulga não

O governo não investe dentro da periferia

Não tem saneamento, comida, nem moradia

Sem centro comunitário de ensino gratuito

Só resta a opção, seguir a vida de bandido

8. Disponível em: https://www.youtube.com/watch?v=jTtbl-_6Jp4. 
Aqui não falta dinheiro pra investir em segurança O Brasil cheio de crack eles esquecem da criança Prevenção não é cadeia é dar oportunidade Pra todo povo humilde que vive na sociedade

Cada governo que entra cada um rouba um pouco Só rombo miserável fica no bolso do povo

Sem dinheiro da merenda e da educação

Esse tipo de pilantra eles não jogam na prisão

De terno e gravata o tratamento é diferente Mas se for filho de pobre couro come de repente Roseana passeando de blindada Hilux

Mas nunca tem dinheiro pra investir na juventude

E cadê a clínica de graça pra reabilitar drogado?

Pra isso falta dinheiro dentro do caixa do Estado

Enche a cidade de arma depois fala de paz

Nesse papo furado ninguém acredita mais

Ai Tio Ted, Bananinha e meu mano Bombadinho Mortos covardemente por um grupo de extermínio

É o plano do Estado pra exterminar a gente

To te dando o papo reto, firme e forte, consciente

Vou te dar uma ideia, faz essa divulgação

Só tem pai de verdade quem tem Deus no coração

Bota fé nessa ideia não desiste meu irmão

Só quem muda nossa história é o autor da salvação

Encerro no sapatinho esse foi o meu poema

Ser feliz é nossa meta não desistir o nosso lema

Sou Sadrak MC, valeu a oportunidade

É o Bonde dos 40 dominando a cidade! 
"Desentoca o arsenal!": a estrutura de sentimento na guerra de fações, analisada...

Neste vídeo gravado no Complexo Penitenciário de Pedrinhas, aparece o MC Sadrak cantando em sua cela, utilizando-se de uma aparelhagem improvisada, rimando em cima de um beat possivelmente baixado da internet. Sadrak é filmado por mais de um de seus companheiros de cela, que portam celulares. Chama atenção a quantidade de pessoas para o espaço minúsculo: além de Sadrak, mais oito detentos aparecem no vídeo, todos jovens de pele parda ou preta. $\mathrm{O} \mathrm{MC}$, ao mesmo tempo em que denuncia o silêncio da mídia, indica reconhecer o proibidão como o veículo de expressão das quebradas e do cárcere. Com um potente conteúdo de denúncia e crítica social, o funk rapidamente viralizou pela internet. Apesar de o número de visualizações dessa postagem no YouTube ser relativamente baixo, o vídeo circulou de maneira significativa em outras redes sociais, como WhatsApp e Facebook, além de ter sido noticiado na imprensa local e nacional. Sobretudo por se tratar de ano eleitoral, em que o debate sobre a situação carcerária no Maranhão estava em pauta, visto a enorme crise no sistema penitenciário do Estado devido às sucessivas rebelióes ocorridas nos anos de 2013 e 2014, de ampla repercussão na imprensa nacional e internacional, com ênfase nas cenas de decapitações e outras barbáries recorrentes nos presídios maranhenses naqueles anos. Nos versos de Sadrak, Roseana Sarney, então governadora do estado, é citada num contexto em que seu governo estava fortemente abalado por grandes escândalos de corrupção, prenúncio da derrota eleitoral que a oligarquia Sarney sofreria para o candidato da oposição, Flávio Dino (PC do B), na disputa pelo poder executivo estadual em 2014.

Em muitos trechos, MC Sadrak ressalta o claro conteúdo classista do punitivismo em voga, levado a cabo por um Estado cujos dirigentes são notórios corruptos que permanecem impunes, a despeito das denúncias que se avolumam. "Esse tipo de pilantra eles não jogam na prisão!”. O compositor também retrata a substituição de investimentos na área social por investimentos na área de segurança, o que caracteriza a substituição do Estado social pelo Estado Penal no neoliberalismo, fenômeno analisado por Wacquant (2008). Na letra há ainda uma crítica à repressão policial: o autor denuncia a existência de uma política estatal de extermínio: "Tio Ted, Bananinha e meu mano Bombadinho/ mortos covardemente por um grupo de extermínio".

Sadrak expressa em sua letra a forma como as oportunidades de ascensão social para a juventude periférica pelos meios "usuais", como acesso a educação e cultura, são frequentemente bloqueadas por uma série de fatores, dentre os quais se destacaria a ausência de políticas sociais por parte do Estado, que afirma não ter dinheiro para "investir na juventude", mas seus dirigentes esbanjam uma vida luxuosa: "Roseana passeando de blindada Hilux/ Mas nunca tem dinheiro pra investir na juventude”. 
Diante desse cenário, só restaria, para a juventude periférica, a via criminal para a sonhada ascensão social: "Só resta a opção, seguir a vida de bandido". No fim das contas, segundo o MC maranhense, o próprio Estado, que empurra a juventude para criminalidade, é também responsável por encarcerar e exterminar esses mesmos jovens, ao mesmo tempo em que dá um tratamento diferenciado para criminosos "de terno e gravata".

Percebemos pela letra de Sadrak que o proibidão se fez um instrumento expressivo poderoso, que acompanhou o crescimento exponencial das facções, se alastrando de ponta a ponta pelo País. Expressões como "Desentoca o arsenal", que inspira o título do trabalho, podem ser encontradas tanto em funks cantados pelo MC Smith, do Rio de Janeiro, que aborda a forma destemida como o Comando Vermelho do Complexo Penha e Alemão enfrenta a polícia, colocando o "caveirão pra voltar de ré!", como também no que apresenta MC Mosquito, que aborda a guerra do Bonde dos 40 contra o PCM na periferia de São Luís.

Nesse contexto, MC Orelha, "persona artística de Gustavo Lopes" (PALOMBINI, 2013a, p. 153), da cidade de Niterói, famoso pelo proibidão conhecido nacionalmente: "Na Faixa de Gaza é assim", afirma numa entrevista que foi menor infrator, porém depois de completar a maioridade, após ter passado por casas de recuperação de menores, pôde alcançar a fama com esse megassucesso que possui mais de 25 milhões de visualizações no YouTube (somadas todas as postagens de sua música), composto quando ele trabalhava como "empregado numa assessoria de cobranças" (PALOMBINI, 2013b, p. 18).

Na Faixa de Gaza, só homem bomba

Na guerra é tudo ou nada

Várias titânio no pente

Colete a prova de bala

Nós desce pra pista pra fazer o assalto

Mas tá fechadão no doze

Se eu tô de rolé 600 bolado

Perfume importado pistola no coldre

9. Disponível em: https://www.youtube.com/watch?v=KZhwSIfsY-4. 
"Desentoca o arsenal!": a estrutura de sentimento na guerra de fações, analisada...

Mulher ouro e poder, lutando que se conquista

Nós não precisa de crédito

Nós paga tudo a vista

É Ecko, Lacoste, é peça da Oakley

Várias camisas de time

Quem tá de fora até pensa que é mole viver do crime

Nós planta humildade, pra colher poder

A recompensa vem logo após

Não somos fora da lei

Porque a lei quem faz é nós

Nós é o certo pelo certo

Não aceita covardia

Não é qualquer um que chega e ganha moral de cria

Consideração se tem

Pra quem age na pureza

Pra quem tá mandado o papo é reto

Bota as peça na mesa

Quantos amigos eu vi ir morar com deus no céu

Sem tempo de se despedir

Mas fazendo o seu papel

Por isso eu vou mandar

Por isso eu vou mandar assim

Comando Vermelho $\mathrm{RL}^{10}$ até o fim

É vermelhão desde pequenininho

Só menor bolado nas favela do Baixinho

10. O Comando Vermelho costuma adicionar a sigla RL, ficando CVRL, em homenagem a Rogério Lemgruber (O Bagulhão ou Marechal), um dos seus fundadores, após sua morte em 1992. 
Não dá, não dá, não dá não

Por isso eu mando assim

Comando Vermelho RL até o fim

É vermelhão desde pequenininho

Só menor bolado nas favela do Baixinho

Nóis tá que tá heim, caralho!

O megassucesso de MC Orelha, que foi rapidamente elevado à condição de hino (PALOMBINI, 2013b), articula de maneira paradigmática várias facetas do universo faccional e do proibidão para os quais chamamos atenção até aqui. Primeiramente, a ascensão social tão sonhada é vista como resultado de uma luta (ou de uma guerra), à qual nos referimos anteriormente, que se dá no cotidiano da favela, mas também no cárcere e na vida como um todo. "Mulher ouro e poder, lutando que se conquista”. Nesse contexto de luta, alimentado por uma sociedade neoliberal que instiga a um comportamento feroz e competitivo, a via criminal é vista como forma legítima de ganhar a vida. E para garantir essa legitimidade, é preciso que haja uma instituição que regule a forma correta (segundo padrões autorreferenciados) de ganhar a vida no mundo do crime. Nesse sentido, as facções são tidas como mantenedoras da lei: "Não somos fora da lei/ Porque a lei quem faz é nós". Essa "lei do crime" está fundada numa postura ético-política: "Nós é o certo pelo certo/ Não aceita covardia”, que toma forma na facção reivindicada: Comando Vermelho. Lembramos que a imposição dessa lei faccional é fundada na guerra. Portanto, a facção é plasmada, nesse e nos proibidões em geral, como a instituição que garante, a partir da união dos irmãos, a vitória na guerra, assegurando assim que o certo prevaleça, segundo os parâmetros autodeterminados pelo próprio crime, delimitando, a partir desse corte ético-politico, aqueles que seriam dignos de desfrutar dessa fraternidade: "consideração se tem, pra quem age na pureza".

Assim, em outros termos, a paz para os irmãos é alcançada mediante a guerra constante travada contra os inimigos. Há no universo do proibidão uma tendência a representar a "paz perpétua como uma guerra perpétua", alinhada com as tendências geopolíticas da guerra do nosso tempo, nos termos delineados por Arantes (2007). A centralidade dessa instituição como cimento dessa luta fica clara ao final, quando o compositor apresenta o orgulho do pertencimento à mais antiga facção brasileira: “Comando Vermelho RL até o fim/ É vermelhão desde pequenininho". Afinal, 
"Desentoca o arsenal!": a estrutura de sentimento na guerra de fações, analisada...

independentemente do que quer que seja, o Comando Vermelho detém um patrimônio simbólico: sua origem na luta, necessariamente violenta (no caso), pela solidariedade na prisão, contra a opressão do Estado. Se ele pode ser eliminado, este significado, não. (PALOMBINI, 2013b, p. 163)

Essa herança simbólica que o Comando Vermelho representa no mundo do crime está bastante presente nas produções artísticas que tematizam a facção. MC Orelha afirma que sua experiência com essa organização, na sua breve passagem pela vida do crime, marcou profundamente o conteúdo e o sentido da sua produção artística. Poderia ser diferente?

Constatamos assim que os sujeitos que compõem o proibidão são diversos e heterogêneos, tais como as periferias onde vivem. O que unifica a heterogeneidade dos proibidões, por mais distintos que sejam seus autores, é a possibilidade de eles assumirem nas suas narrativas o protagonismo do bandido, sem que por isso recaia um julgamento valorativo sobre suas ações, e, principalmente, sem que os criminosos percam sua humanidade. Assim se contrapõem ao "discurso de alguns agentes de Estado e setores da mídia corporativa, [onde] o traficante é construído como um ser abjeto que praticamente abre mão de sua humanidade ao lançar mão dessas práticas consideradas criminosas" (NOVAES, 2016, p. 12). Divergindo desse discurso vigente, no proibidão, o bandido recuperaria essa humanidade perdida, porque seus versos "não retiram dos bandidos sua 'humanidade' e ressaltam a insuficiência das demarcações normativas estatais para dar conta destes sujeitos" (NOVAES, 2016, p. 55).

\section{CONSIDERAÇÕES FINAIS}

Entendemos que o funk proibidão nos revela a estrutura de sentimento de uma juventude pobre e de periferia, que, submetida a uma brutal condição de pauperização e segregação social e racial da era neoliberal, com consciência de que qualquer outra via de ascensão econômica está bloqueada ou (no mínimo) extremamente dificultada, é levada a acreditar que somente mediante o poder das armas e com a gestão de mercados ilegais é possível alcançar um padrão de vida confortável, representado nas letras pelo acesso a roupas de marca, carros de luxo, cordões de ouro e armas automáticas: "É Ecko, Lacoste, é peça da Oakley /Várias camisas de time/ Quem tá de fora até pensa que é mole viver do crime", diz Orelha. É necessário frisar que, para essa juventude, 
esses bens não são simples itens de consumo, são signos que lhes conferem respeito e dignidade como seres humanos. Mais do que ânsia consumista, a posse desses signos tem a ver com respeito e autoestima, com aceitação pelos seus e com a "conquista" das mulheres. Em suma, para eles significa escapar da invisibilidade social que a condição de jovens pobres e favelados lhes confere. "Enquanto o cifrão falar mais alto e fizer parte da autoestima/ vai ter uma 'Faixa de Gaza' sempre em uma nova esquina” (MC Orelha, "Faixa de Gaza 2"). É necessário salientar que esta estrutura de sentimento plasmada nos funks de Orelha, Sadrak e tantos outros está presente de norte a sul do Brasil, atravessando os particularismos locais e as siglas que subdividem esse mundo. Essa nova configuração nacional do crime foi muito bem exposta por Manso e Dias (2018, p. 230, negrito nosso):

Essa nova configuração criminal passou a dar o tom da violência armada brasileira, estruturada numa conexão prisão-quebrada em quase todos os estados do Brasil. O entra e sai da prisão, associado ao comércio das drogas, formou uma visão de mundo comum, com gírias, gestos, valores e expressões semelhantes, que se interligaram graças aos novos meios de comunicação. "É nóis que tá", por exemplo, é uma expressão falada nas quebradas de norte a sul. A valorização do espírito guerreiro, a disposição para o combate, a ostentação de bens de consumo e de armas e o ódio ao Estado passaram a seduzir cada vez mais jovens, independentemente dos limites dos Estados. Tudo, agora, reproduzido em vídeo e compartilhado nas redes sociais. Nesse novo contexto, os trejeitos e falas de um representante da cena criminal acreana, cantando proibidão numa favela de Rio Branco, dançando para uma câmera de celular, são parecidos com os dos jovens de Joinville, que ostentam suas armas celebrando a vida do crime.

Dessa maneira, entendemos que a estrutura de sentimento que rastreamos no proibidão está presente em escala nacional como síntese da articulação de múltiplas experiências que são comuns para estes setores sociais: "o que pode estar acontecendo nessas ocasiões é que uma experiência que é de fato bastante ampla subitamente encontra uma forma semântica que a articula" (WILLIAMS, 2013, p. 160). Essa experiência, uma vez plasmada nas músicas, passa a compor a estrutura interna das obras ora analisadas, "o lugar peculiar da estrutura de sentimento é a equivalência sem fim que deve ocorrer, no processo da consciência, entre o articulado e o vivido" (WILLIAMS, 2013, p. 164). Dessa maneira, à luz das pistas deixadas por Williams, entendemos o proibidão e o seu mundo social de uma forma 
"Desentoca o arsenal!": a estrutura de sentimento na guerra de facções, analisada...

"dialeticamente íntegra", isto é, eles se interpenetram, os elementos sociais se tornam internos aos proibidões, ao passo que os proibidões se conectam ao contexto social, engendrando novas relações e novas experiências sensíveis.

\section{REFERÊNCIAS}

ARANTES, P. Extinção. São Paulo: Boitempo, 2007. (Coleção Estado de Sítio).

BIONDI, K. Proibido roubar na quebrada: território, hierarquia e lei no PCC. São Paulo: Terceiro Nome, 2018.

CEVASCO, M. E. Para ler Raymond Williams. São Paulo: Paz e Terra, 2001.

CYMROT, D. "Proibidão" de Colarinho-Branco. In: BATISTA, C. B. (Org.). Tamborzão: olhares sobre a criminalização do funk. Rio de Janeiro: Revan, 2013.

FACINA, A. Quem tem medo do "proibidão"? In: BATISTA, C. B. (Org.). Tamborzão: olhares sobre a criminalização do funk. Rio de Janeiro: Revan, 2013.

FELTRAN, G. de S. Fronteiras de tensão: política e violência nas periferias de São Paulo. São Paulo: Editora Unesp, 2011.

. Irmãos: uma história do PCC. São Paulo: Companhia das Letras, 2018.

HIRATA, D. V.; GRILLO, C. C. Sintonia e amizade entre patrões e donos de morro: perspectivas comparativas entre o comércio varejista de drogas em São Paulo e no Rio de Janeiro. Tempo Social, Revista de Sociologia da USP, São Paulo, v. 29, n. 2, 2017. Disponível em: <http://www.scielo.br/ pdf/ts/v29n2/1809-4554-ts-29-02-0004.pdf> Acesso em: 08 jul. 2019.

KEHL, M. R. Da lama ao caos: a invasão da privacidade na música do grupo Nação Zumbi. In.: CAVALCANTE, B.; STARLING, H.; EISENBERG, J. (Org.). Decantando a República. v. 3: Inventário histórico e político da canção popular. Rio de Janeiro: Nova Fronteira; São Paulo: Fundação Perseu Abramo, 2004.

LESSING, B. As facções cariocas em perspectiva comparativa. Novos Estudos - CEBRAP, Dossiê Segurança Pública, v. 8o, p. 43-62, mar. 2008. Disponível em: <http://www.scielo.br/pdf/nec/ n8o/aoin8o.pdf > Acesso em: o8 jul. 2019.

LOPES, A. C.; FACINA, A. Cidade do funk: expressões da diáspora negra nas favelas cariocas. Revista do Arquivo Geral da Cidade do Rio de Janeiro, n. 6, p. 193-206, 2012. Disponível em: <http:// www.cult.ufba.br/wordpress/24340.pdf> Acesso em: 08 jul. 2019.

MANSO, B. P.; DIAS, C. N. A guerra: a ascensão do PCC e o mundo do crime no Brasil. São Paulo: Todavia, 2018.

MARQUES, A. "Liderança”, "proceder” e "igualdade”: uma etnografia das relações políticas no Primeiro Comando da Capital. Etnográfica, v. 14, n. 2, p. 311-335, jun. 2010. Disponível em: $<$ https://journals.openedition.org/etnografica/303> Acesso em: 08 jul. 2019.

MATTOS, C. dos S. Uma etnografia da expansão do mundo do crime no Rio de Janeiro. Revista Brasileira de Ciências Sociais, v. 31, n. 91, 2016. Disponível em: <http://www.scielo.br/pdf/rbcsoc/ v31n91/o102-6909-rbcsoc-3191102016.pdf> Acesso em: o8 jul. 2019. 
NOVAES, D. Funk proibidão: música e poder nas favelas cariocas. 137 f. Dissertação (mestrado) Museu Nacional, Programa de Pós-Graduação em Antropologia Social, Universidade Federal do Rio de Janeiro, Rio de Janeiro, 2016. Orientadora: Adriana Facina. Coorientador: Carlos Palombini PALOMBINI, C. Entrevista com Gustavo Lopes (MC Orelha). In: BATISTA, C. B. (Org.). Tamborzão: olhares sobre a criminalização do funk. Rio de Janeiro: Revan, 2013 a.

PALOMBINI, C. Musicologia e direito na Faixa de Gaza. In: BATISTA, C. B. (Org.). Tamborzão: olhares sobre a criminalização do funk. Rio de Janeiro: Revan, $2013 \mathrm{~b}$.

SANTOS, T. dos (MC Praga). A guerra. In: BATISTA, C. B. (Org.). Tamborzão: olhares sobre a criminalização do funk. Rio de Janeiro: Revan, 2013.

SOUZA, J. As metamorfoses do malandro. In: CAVALCANTE, B.; STARLING, H.; EISENBERG, J. (Org.). Decantando a República. v. 3: Inventário histórico e político da canção popular. Rio de Janeiro: Nova Fronteira; São Paulo: Fundação Perseu Abramo, 2004.

THOMPSON, E. P. A formação da classe operária inglesa I: a árvore da liberdade. 2. ed. Rio de Janeiro: Paz e Terra, 1987.

VIEIRA, T. B. Proibidão de boca em boca: representações sociais no funk proibido. Rio de Janeiro: UFRJ, 2012.

WACQUANT, L. O lugar da prisão na administração da pobreza. Novos Estudos - Cebrap, n. 8o, p. 9-19, mar. 2008. Disponível em: <http://www.scielo.br/pdf/nec/n8o/ao2n8o.pdf > Acesso em: o8 jul. 2019.

WILLIAMS, R. Marxismo e literatura. Rio de Janeiro: Zahar, 1979. . A política e as letras: entrevistas da New Left Review. Tradução de André Giset. 1. ed. São Paulo: Editora Unesp, 2013.

\section{SOBRE O AUTOR}

Luiz Eduardo Lopes Silva possui graduação em História Licenciatura Plena (2006-2010) e Mestrado em História Social (2012-2014), ambos pela Universidade Federal do Maranhão (UFMA). Atualmente é aluno do Programa de Pós-Graduação em Educação da Universidade Federal Fluminense (UFF) em nível de doutorado. É professor efetivo da Universidade Federal do Maranhão (UFMA), Campus Universitário de Pinheiro. É também professor da rede pública estadual do Maranhão (ensino médio). Tem experiência na área de História Contemporânea. Concentra-se na pesquisa dos seguintes temas: luta de classes em suas diversas manifestações, criminalidade urbana violenta, estética da violência, facções e processos de institucionalizações no mundo do crime; neoliberalismo e encarceramento em massa, funk proibidão, rap, hip hop e produção cultural nas periferias, história dos usos de psicoativos, proibicionismo, Thompson 
"Desentoca o arsenal!": a estrutura de sentimento na guerra de facções, analisada...

e Raymond Williams, cultura e marxismo, fundamentos teóricos da obra marxiana, estética e ontologia, situacionistas, marxismo libertário.

E-mail:edu_lsilva@hotmail.com.

Recebido em o1 de julho de 2019 e aprovado em 23 de setembro de 2019. 